\title{
Morphology Laterality
}

National Cancer Institute

\section{Source}

National Cancer Institute. Morphology Laterality. NCI Thesaurus. Code C117621.

A qualifier for the side of the body the morphology assessment is performed. 